\title{
Interaction of perfluorooctanoic acid with human serum albumin Ling-Ling $\mathrm{Wu}^{1}$, Hong-Wen $\mathrm{GaO}^{2}$, Nai-Yun Gao ${ }^{1}$, Fang-Fang Chen ${ }^{2}$ and Ling Chen*1
}

Address: ${ }^{1}$ State Key Laboratory of Pollution Control and Resource Reuse, College of Environmental Science and Engineering, Tongji University, Shanghai 200092, PR China and ${ }^{2}$ Key Laboratory of Yangtze River Water Environment of Ministry of Education, College of Environmental Science and Engineering, Tongji University, Shanghai 200092, PR China

Email: Ling-Ling Wu - wulleco@hotmail.com; Hong-Wen Gao - hwgao@tongji.edu.cn; Nai-Yun Gao - gaonaiyun@sina.com; FangFang Chen - eboocff@163.com; Ling Chen* - chenling@tongji.edu.cn

* Corresponding author

Published: 14 May 2009

BMC Structural Biology 2009, 9:31 doi:10.1186/1472-6807-9-31

This article is available from: http://www.biomedcentral.com/1472-6807/9/3।

(C) 2009 Wu et al; licensee BioMed Central Ltd.

This is an Open Access article distributed under the terms of the Creative Commons Attribution License (http://creativecommons.org/licenses/by/2.0), which permits unrestricted use, distribution, and reproduction in any medium, provided the original work is properly cited.
Received: 9 March 2009

Accepted: I4 May 2009

\begin{abstract}
Background: Recently, perfluorooctanoic acid (PFOA) has become a significant issue in many aspects of environmental ecology, toxicology, pathology and life sciences because it may have serious effects on the endocrine, immune and nervous systems and can lead to embryonic deformities and other diseases. Human serum albumin (HSA) is the major protein component of blood plasma and is called a multifunctional plasma carrier protein because of its ability to bind an unusually broad spectrum of ligands.
\end{abstract}

Results: The interaction of PFOA with HSA was investigated in the normal physiological condition by equilibrium dialysis, fluorospectrometry, isothermal titration calorimetry (ITC) and circular dichroism (CD). The non-covalent interaction is resulted from hydrogen bond, van der Waals force and hydrophobic stack. PFOA binding to HSA accorded with two-step binding model with the saturation binding numbers of PFOA, only I in the hydrophobic intracavity of HSA and 12 on the exposed outer surface. The interaction of PFOA with HSA is spontaneous and results in change of HSA conformation. The possible binding sites were speculated.

Conclusion: The present work suggested a characterization method for the intermolecular weak interaction. It is potentially useful for elucidating the toxigenicity of perfluorochemicals when combined with biomolecular function effect, transmembrane transport, toxicological testing and the other experiments.

\section{Background}

It is well known that the Teflon event involving the Dupont Company of USA drew serious international attention to perfluorooctanoic acid (PFOA) [1]; PFOA is formed from the raw materials used in the production of Teflon-lined non-stick cooking appliances. Fluoropolymers such as Teflon have very good performances e.g. as fire retardants and for oil and fat resistance; their byprod- ucts such as PFOA can be formed by cooking, burning and environmental degradation. PFOA is still widely used in basic processes in the aviation, automobile, building materials, chemicals, electronic, semiconductor and textile industries. It is persistent and non-biodegradable and becomes widely distributed in nature, e.g. water [2], biological bodies [3], human tissues [4] and foods [5]. It can certainly enter the gastrointestinal tract via the intake of 
foods and water and then it is absorbed and permeates into the blood and various tissues. Sampling studies have revealed the presence of PFOA in the bloods of over $90 \%$ of US residents [6]. It may have serious effects on the endocrine, immune and nervous systems and it can be delivered to the fetus through the umbilical cord and can accumulate [7]. It can also cause cancers of the liver, testis, pancreatic and mammary glands [8], and can lead to embryonic deformities and other diseases $[9,10]$. In recent years, PFOA has become a significant issue in many aspects of environmental ecology, toxicology, pathology and life sciences [11,12].

Human serum albumin (HSA) is a major protein component of blood plasma but is also found in the interstitial fluid of body tissues. In mammals, albumin is synthesized by the liver and has a half-life of 19 days in the circulation [13]. It is the major contributor to the oncotic pressure of the blood plasma [14]. It is called a multifunctional plasma carrier protein because of its ability to bind an unusually broad spectrum of ligands e.g. inorganic ions, various drugs, amino acids, fatty acids, etc. Binding to HSA facilitates their transport throughout the circulation [15]. Without doubt, interaction of any toxicant with HSA influences the transport of nutrients and drugs. Recently, studies have been conducted on the binding of organic contaminants or toxins to HSA e.g. arazine [16], ochratoxin [17], methyl parathion [18] and arsenic [19]. Bindings of PFOA to biomacromolecular such as rat and Human plasma proteins [20], rat liver-form and kidneyform alpha 2u-globulins [21], have been investigated at room temperature. The interaction of organic contaminants and HSA is always affected by various environmental conditions such as $\mathrm{pH}$, strength and temperature [22]. In this work, we investigated the interaction of PFOA with HSA by equilibrium dialysis, fluorospectrometry, isothermal titration calorimetry (ITC) and circular dichroism (CD) under normal physiological condition, $\mathrm{pH} 7.40$ and $0.15 \mathrm{M}$ electrolyte and $37^{\circ} \mathrm{C}$. The object is to analyze the interaction forces, sites and type and then further understand the toxigenicity of PFOA.

\section{Results and discussion Equilibrium dialysis of PFOA}

The equilibrium dialysis method was used to investigate the interaction of PFOA with HSA. The PFOA concentration in the dialysis solution was measured at $37^{\circ} \mathrm{C}$ at various dialysis times with no protein in the membrane. The PFOA dialysis rate approaches $90 \%$ at $2 \mathrm{~h}$ and exceeds $98 \%$ after 4 h (Fig. 1). PFOA passes freely through the semi-permeable membrane until equilibrium reached. HSA solution was put into the dialysis membrane as dialysate instead of PFOA, but it was found only in the dialysis bag. Therefore, the equilibrium dialysis is suitable for investigating the interaction of PFOA with HSA. The dial-

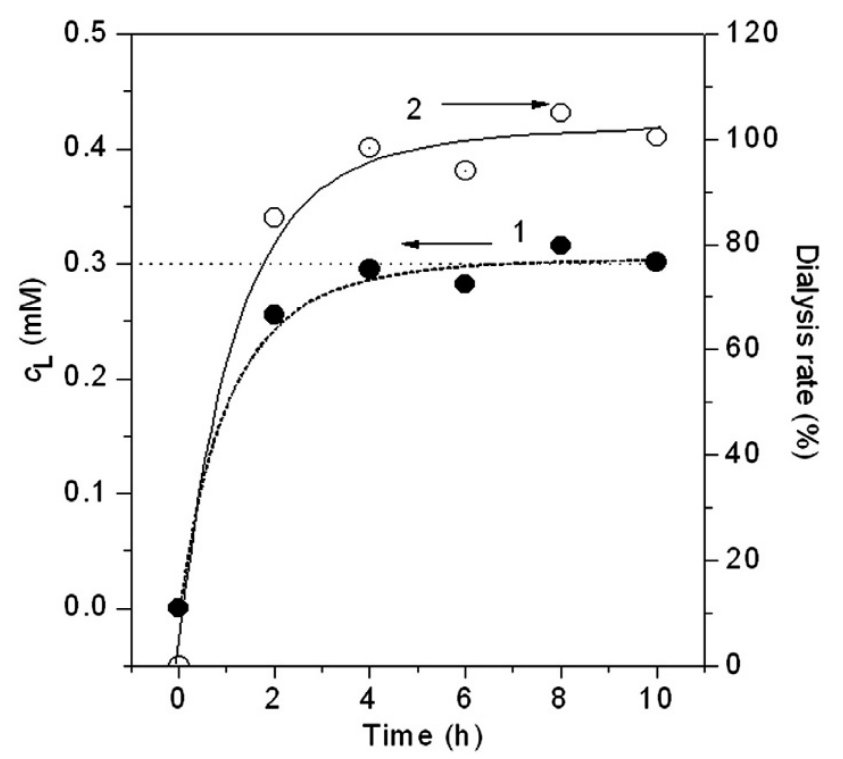

Figure I

Equilibrium dialysis of PFOA: (I) - Change of PFOA concentration $\left(C_{L}\right)$ in the dialysis solution initially containing $9.0 \mathrm{ml}$ of $\mathrm{pH}$ 7.40 BR buffer and $27.0 \mathrm{ml}$ of distilled water, while $3.0 \mathrm{ml}$ of $\mathrm{pH}$ 7.40 BR buffer, 3.0 $\mathrm{ml}$ of $5.00 \mathrm{Mm}$ PFOA and $4.0 \mathrm{ml}$ of distilled water were mixed in the bag at the beginning of the dialysis. PFOA in the dialysis solution was determined at various dialysis times. (2) - Variation of the PFOA dialysis rate calculated by (initial molarity of PFOA in bag $-4 c_{L}$ )/initial molarity of PFOA in dialysis membrane, which was used to estimate the dialysis equilibrium time.

ysis solution was sampled and measured spectrophotometrically to determine the PFOA concentration after more than $4 \mathrm{~h}$ of dialysis.

\section{Characterization of the interactions of PFOA with HSA}

The interaction of PFOA with HSA is summarized as follows:

$\begin{array}{llll} & N \text { PFOA }+ & \text { HSA } \rightleftharpoons & \text { HSA }(\text { PFOA })_{N} \\ \text { Initiation } & c_{\mathrm{L} 0} & c_{\mathrm{M} 0} & 0 \\ \text { Equilibrium } & c_{\mathrm{L}}=c_{\mathrm{L} 0}-N c_{\mathrm{M} 0} & c_{\mathrm{M}} \rightarrow 0 & c_{\mathrm{M} 0}\end{array}$

Both $c_{\mathrm{L} 0}$ and $c_{\mathrm{M} 0}$ are the initial mole concentrations of PFOA and HSA, $c_{\mathrm{L}}$ is the equilibrium concentration of PFOA described above. $N$ is the saturation binding number of PFOA. The effective fraction $(f)$ of PFOA bound to HSA and its molar binding ratio $(\gamma)$ are calculated by the relations: $f=1-c_{\mathrm{L}} / c_{\mathrm{L} 0}$ and $\gamma=f c_{\mathrm{L} 0} / c_{\mathrm{M} 0}$. The $\gamma$ value will approach $N$ with increasing PFOA.

In fact, $\mathrm{pH}$ varies widely among normal tissues in the human body. For example, less than $\mathrm{pH} 3.0$ in gastric fluid, pH 6.0 in liver and saliva, pH $4.0-5.0$ on the skin 
and around $\mathrm{pH} 7.40$ in blood and intestinal tract. Normal human temperature is $37^{\circ} \mathrm{C}$ and the electrolyte concentration is between 0.8 and $0.9 \%$ (approximately $0.15 \mathrm{M}$ ). In this present work, the experiments were conducted in $0.15 \mathrm{M} \mathrm{NaCl}$ at $\mathrm{pH} 7.40$ at $37^{\circ} \mathrm{C}$. By measuring a series of PFOA solutions containing known concentrations of HSA at $\mathrm{pH} 7.40$, the $f$ and $\gamma$ values were calculated according to the above equations. The $f$ decreases linearly with increasing PFOA concentration from curve 1 in Fig. 2, but $\gamma$ increases from curve 2. The binding of PFOA approaches to a constant maximum at 13 when $c_{\mathrm{L} 0} / c_{\mathrm{M} 0}$ is more than 20 from curve 2 . The number of amino acid residues positively charged e.g. Lys, His and Arg is 98 in HSA, which is no correlation with such an $N$ value. Different from a sulfonic azo ligand [23], the PFOA binding to HSA doesn't results from ion-pair attraction. Strong intermolecular forces e.g. hydrogen bond, van der Waals forces and hydrophobic interaction may be involved. The Temkin isothermal model, $\frac{\gamma}{N}=-\frac{R T}{\Delta Q} \ln \left(K_{a} c_{L}\right) \quad\left(K_{\mathrm{a}}\right.$ - adsorption constant, $\mathrm{M}^{-1}, \Delta Q$ - saturation adsorption energy, $T$ - the Kelvin temperature and $R$ - the gas constant, $8.314 \mathrm{~J} \mathrm{~mol}^{-}$
${ }^{1} \mathrm{~K}^{-1}$ ) was used to fit the above experimental data. From curve 3 (Fig. 2), the interaction of PFOA with HSA corresponds to chemical monolayer adsorption. Both $\Delta Q$ and $K_{\mathrm{a}}$ were calculated to be $-3.89 \mathrm{~kJ} / \mathrm{mol}$ and $3.12 \times 10^{4} \mathrm{M}^{-1}$. The adsorption of PFOA on HSA is exothermic and noncovalent [24], i.e. no strong bond was formed between PFOA and HSA.

In order to understand the mechanism of PFOA-HSA binding, some detailed thermodynamic data are needed. The ITC measurement may provide information on thermodynamic quantities such as enthalpy and heat capacity changes during the molecular interaction directly from the heat produced by the reaction, and have been used to study, for example, protein interactions [25], DNA triplex formation [26] and HIV protease activity [27]. Fig. 3A depicts a typical isothermal titration profile obtained by injecting PFOA into the ITC cell containing HSA. The resulting values were plotted as a function of $c_{\mathrm{L} 0} / c_{\mathrm{M} 0}$ and fitted to a two-step sequential binding model by a nonlinear least squares method (Fig. 3B). Values for the equilibrium constant $\left(K_{b}\right)$, enthalpy change $(\Delta H)$ and entropy change $(\Delta S)$ of the PFOA-HSA reaction were obtained and
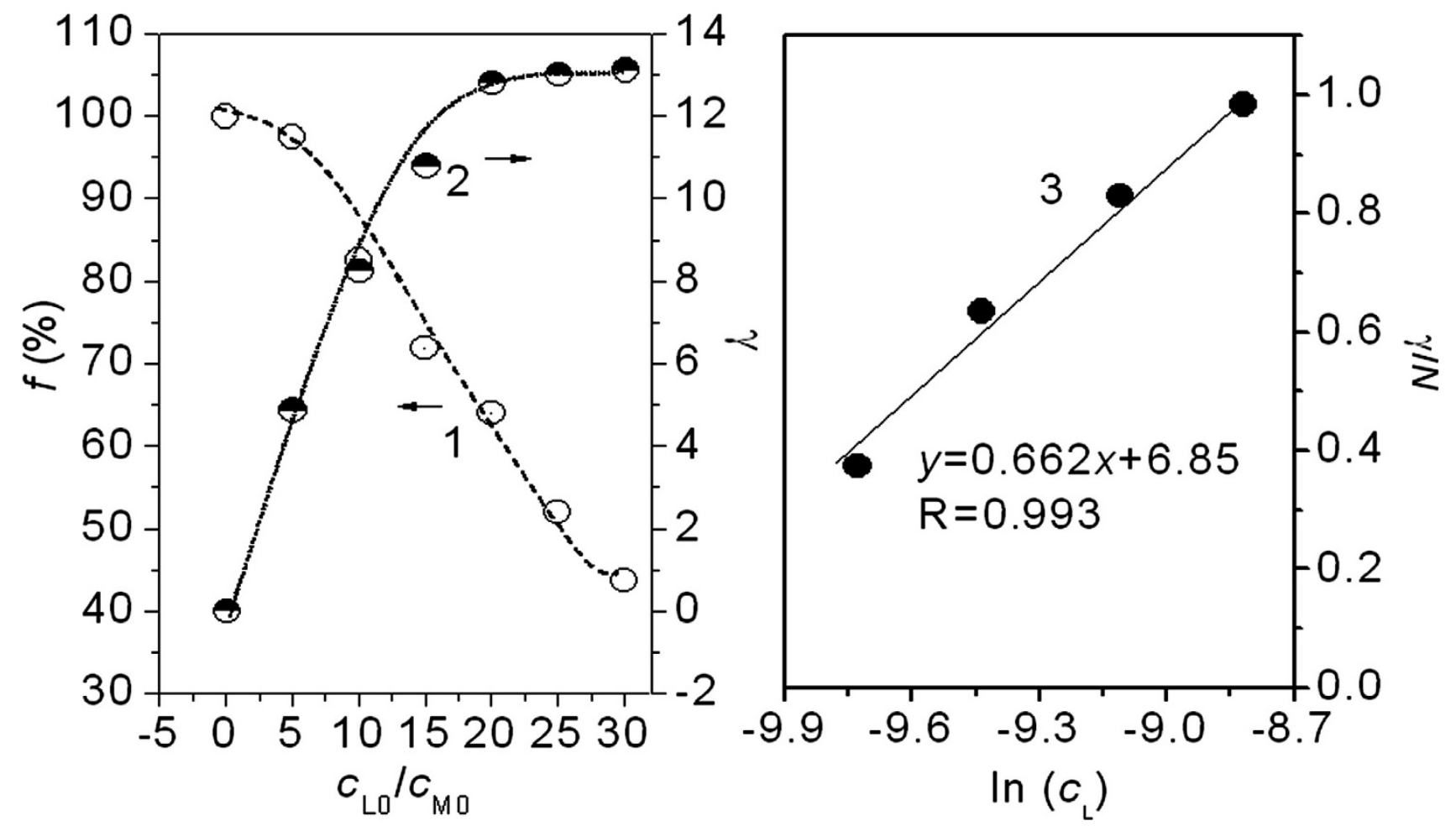

Figure 2

Effect of PFOA (initial concentration from 0 to $1.75 \mathrm{mM}$ in the dialysate) on binding to HSA, initially 0.033 mM. (I) and (2) $-f$ and $\gamma$ of PFOA; (3) - plots $\gamma / \mathrm{N}$ vs. $\ln \left(\mathrm{c}_{\mathrm{L}}\right)$. All the solutions were in $0.15 \mathrm{M} \mathrm{NaCl}$ at $\mathrm{pH} 7.40$ at $37^{\circ} \mathrm{C}$ 


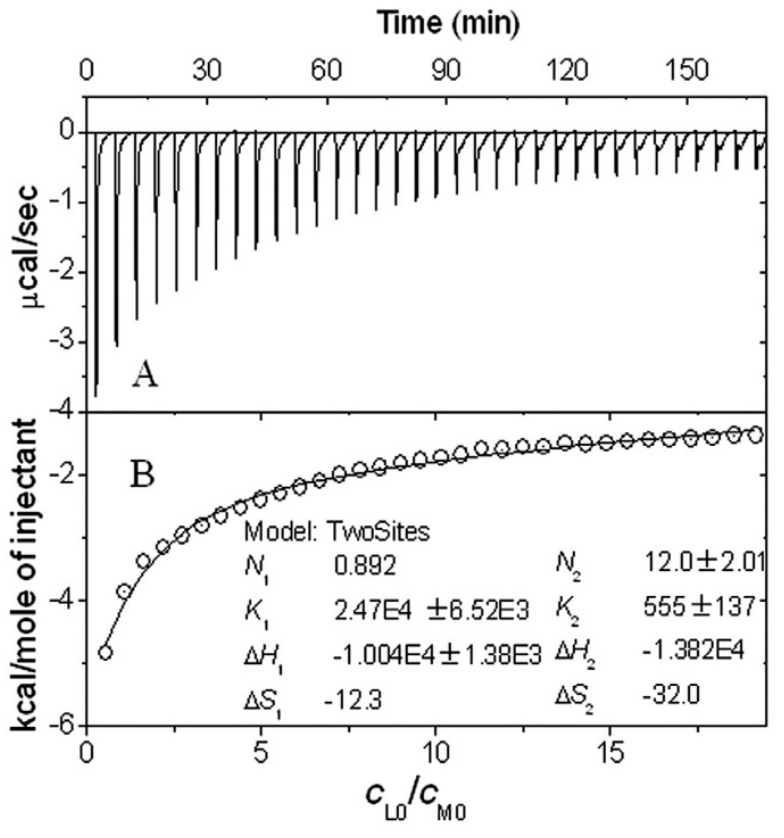

Figure 3

(A) ITC titration profile of PFOA-HSA binding at $\mathrm{pH}$ 7.40. The temperature was $37^{\circ} \mathrm{C}$ and all the solutions contained $0.15 \mathrm{M} \mathrm{NaCl}$. Each pulse corresponds to a $6.0-\mu \mathrm{l}$ injection of $2.50 \mathrm{mM}$ PFOA into the ITC cell $(\mathrm{I} .4685 \mathrm{ml})$ containing $0.010 \mathrm{mM}$ HSA. (B) The area of each peak in A was integrated and corrected for the heat of dilution, which was estimated in a separate experiment by injecting the PFOA into the buffer.

calculated by the Gibbs free energy $(\Delta G)$ equation: $\Delta G=$ $R T \ln K_{\mathrm{b}}=\Delta H-T \Delta \mathrm{S}$. The thermodynamic parameters derived from this curve are summarized in Table 1. Because both $\Delta H_{i}$ values are much less than $60 \mathrm{kcal} / \mathrm{mol}$ [24], the non-covalent binding of PFOA to HSA is confirmed.

PFOA is more lipophilic in aqueous solution and it decreased obviously the aqueous surface intensity. Fifteen electrophilic F-groups in PFOA can attract strongly the lone pair electrons of polar side groups of peptide chain, e.g. FUN and FUO halogen bonding [28]. HSA is consisted of three homologous all $\alpha$-helical domains (I-III), each divided into two subdomains [14]. All the helixic subdomains are distributed round a hydrophobic intrac- avity and the hydrophilic side groups of HSA exposed on the outer surface. In the first step, only one PFOA molecule bound on HSA (Table 1). The $f$ of PFOA is always more than $90 \%$ from curve 1 in Fig. 2 when the $c_{\mathrm{L} 0} / c_{\mathrm{M} 0}$ is less than 5 . Therefore, the first step is complete at approximately 1.5 of $c_{\mathrm{L} 0} / c_{\mathrm{M} 0}$. HSA binding PFOA caused the entropy decreasing $\left(\Delta S_{1}<0\right)$ in this step. The refolding of HSA occurred by resuming the released heat. From $\Delta G_{1}$ value, the PFOA-HSA reaction is spontaneous. Moreover, the higher $K_{\mathrm{b}, 1}$ value indicated that the binding of the first PFOA molecule to HSA is firmer. From curve 1 to 9 in Fig. 4 , the blue shift of peak emission wavelength from 345 to $335 \mathrm{~nm}$ indicated that the static quench of the HSA's intrinsic fluorescence occurred in the presence of PFOA, specially obviously when $c_{\mathrm{LO}} / c_{\mathrm{M} 0}$ is less than 2 . Thus, the first PFOA molecule may bind to the side group of Tyr. As a result, the deformable linear PFOA may insert into the hydrophobic intracavity of HSA and bridge between subdomains IIA and IIB (No. 1 in Fig. 5) across Trp 213 by

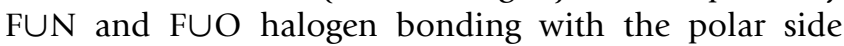
groups of Asn, Gln, Asp, Glu, Arg, His, Tyr and Trp and hydrophobic interaction with the non-polar side groups, e.g. Val, Leu, Met, Ala and Ile. The first step binding of PFOA to HSA is similar to that of long chain fatty acids to HSA [14].

Besides a long carbon chain, PFOA has strong extensibility on interface of water - particles so that it may spread on the exposed outer surface of HSA. When $c_{\mathrm{L} 0} / c_{\mathrm{M} 0}$ is more than 2, PFOA began to bind on the hydrophilic surface of HSA till a saturation $\left(N_{2}=12\right)$ via the polar bonds e.g.

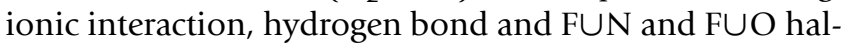
ogen bonding (Fig. 3B). By comparison of $N$ obtained by equilibrium dialysis (Fig. 2) and that $\left(N=N_{1}+N_{2}=13\right)$ obtained by ITC (Fig. 3B), two methods achieves the same result. From the higher $\Delta H_{2}$ value, the binding sites of PFOA may bridge between any two helixes all over the outer surface of HSA (Fig. 5). From $\Delta G_{2}$ value (Table 1), the PFOA-HSA reaction is spontaneous. In the 2nd step, the binding of PFOA to HSA caused an obvious entropy decreasing, i.e. more negative $\Delta S_{2}$ (Table 1), the HSA structure changed refolding.

By comparison of the emission spectra in Fig. 4, the obvious blue shift of peak wavelength was found when $c_{\mathrm{LO}} / c_{\mathrm{M} 0}$ is more than 2. This indicates an obvious change of HSA conformation, too. As a result, the interaction of PFOA

Table I: Thermodynamic property of the HSA-PFOA interaction at $\mathrm{pH} 7.40$ at $37^{\circ} \mathrm{C}$

\begin{tabular}{ccccccc}
\hline$i$-th step & $c_{\mathrm{LO} 0} / c_{\mathrm{MO}}$ & $N_{i}$ & $\begin{array}{c}K_{b, i} \\
\left(10^{3} \mathrm{M}^{-1}\right)\end{array}$ & $\Delta H_{i},(\mathrm{kcal} / \mathrm{mol})$ & $\begin{array}{c}\Delta \mathrm{S}_{\mathrm{i}} \\
(\mathrm{cal} /(\mathrm{mol} \cdot \mathrm{K}))\end{array}$ & $\begin{array}{c}\Delta G_{i} \\
(\mathrm{kcal} / \mathrm{mol})\end{array}$ \\
\hline $\mathrm{I}$ & $<1.5$ & $\mathrm{I}$ & $24.7 \pm 6.5$ & -10.0 & -12.3 & -6.19 \\
2 & $1.5-20$ & 12 & $0.55 \pm 0.14$ & -13.8 & -32.0 & -3.88
\end{tabular}




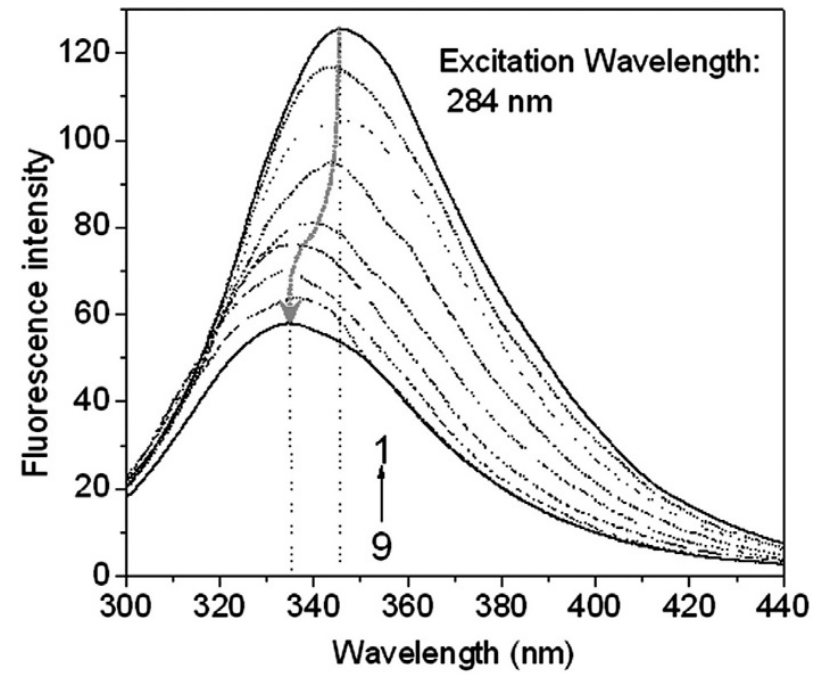

Figure 4

Variation of the intrinsic fluorescence of HSA $\left(\mathrm{C}_{\mathrm{MO}}=\right.$ $0.010 \mathrm{mM})$ with increase of PFOA $\left(c_{L 0}=0-0.300\right.$ $\mathbf{m M})$ at pH 7.40. From (I) to (9): $\mathrm{c}_{\mathrm{L} 0} / \mathrm{c}_{\mathrm{MO}}$ is $0,1.0, \mathrm{I} .5,2.0$, 3.0, 5.0, 10.0, 20.0 and 30.0.

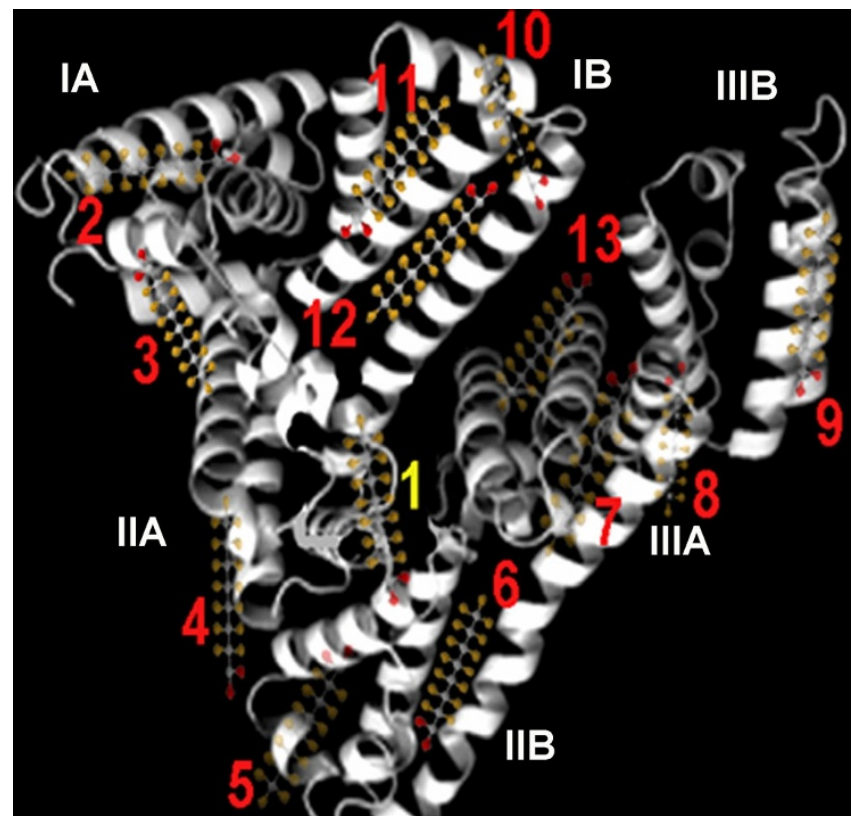

Figure 5

Cartoon illustrating the binding of PFOA to HSA. (I) - possible PFOA binding site in the Ist step; from (2) to (I3) - PFOA binding sites in the 2nd step. with HSA is assignable under normal physiological condition. In addition, the $\beta$-pleated sheet content of HSA decreased obviously and its $\alpha$-helix increased by $15 \%$ in the presence of PFOA from the change of CD spectra of HSA (Fig. 6). Thus, the second step in PFOA binding changed a substantial part of the $\beta$-pleated sheet of HSA into $\alpha$-helix form. Without doubt, such a binding would cause a great change of HSA structure and affect the function of HSA in blood.

\section{Conclusion}

The current work investigated the interaction of PFOA with HSA in the normal physiological acidities of blood and intestinal tract tissue where PFOA molecules may be present. The interaction of PFOA with HSA accorded with the Langmuir isothermal model in two-step sequence, in which only one PFOA molecule entered the hydrophobic intracavity in the first step and 12 PFOA molecules binding on the hydrophilic outer surface in the second step. The interaction of PFOA and HSA is spontaneous and the non-covalent bond results in change of HSA conformation. The possible binding sites were also speculated. The present work proposed a determination and characterization method for the intermolecular weak interaction. If combined further with the other experiments e.g. biomolecular function effect [29], cell membrane transport of contaminant [30] and toxicological testing [31], it is more helpful for elucidating the toxigenicity of perfluorochemicals.

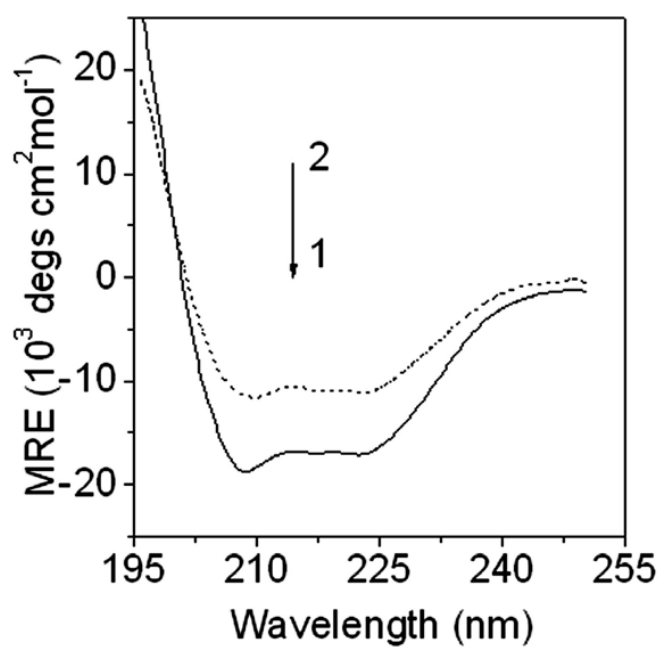

Figure 6

Molar ellipiticity curves for HSA $(0.010 \mathrm{mM})$ solutions at pH 7.40. (I) - no PFOA and (2) - $1.0 \mathrm{mM}$ PFOA. 


\section{Methods \\ Instruments and chemicals}

Model S-4100 spectrophotometer (Sinco Co., Korea), which was computer-controlled by Labpro Plus firmware (Version 060105); Model MSC-ITC system (MicroCal Inc., USA) with measurement software; Model J-715 CD Spectropolarimeter (Jasco Instrum., Japan) with secondary structure Estimation-Standard Analysis Measurement software (715/\#B014460524, JASCO); Model RC 30 - 5K semi-permeable membrane (Molecular Weight Cut Off 5 $\mathrm{KDa}$, Shanghai Green Bird STD). Both $0.100 \mathrm{mM}$ HSA (Sigma) was prepared and stored at $4^{\circ} \mathrm{C}$. The other solutions were prepared: a standard PFOA solution (New Jersey, USA) (5.00 mM); Britton-Robinson (BR) buffers ( $\mathrm{pH}$ 7.40); ECR (1.00 mM, A. R., Sigma) solution; CPC (1.00 $\mathrm{mM}$, purity > 99\%, Shanghai Reagents).

\section{Determination of PFOA}

A simple and rapid spectrophotometry method for determining PFOA was developed. The anionic color ligand eriochrome cyanine $\mathrm{R}$ (ECR) and cationic surfactants cetylpyridinium chloride (CPC) were employed to determine PFOA. The detailed analytical procedure was described by [32].

\section{Equilibrium dialysis}

Unlike a color ligand [23], PFOA does not absorb visible light strongly so the interaction cannot be characterized by VIS spectrophotometry. Therefore, equilibrium dialysis was used. We designed a new dialysis device (Fig. 7), where $12.0 \mathrm{ml}$ solutions containing $3.0 \mathrm{ml}$ of BR buffer (pH 7.40), $0.15 \mathrm{M} \mathrm{NaCl}, 0.033 \mathrm{mM} \mathrm{HSA}\left(c_{\mathrm{M} 0}\right)$, a series of PFOA concentrations $\left(c_{\mathrm{L} 0}\right)$ and distilled water were mixed and transferred to dialysis bags (1). A solution $(36.0 \mathrm{ml})$ containing $0.15 \mathrm{M} \mathrm{NaCl}, 9.0 \mathrm{ml}$ of BR buffer and distilled water was added to the dialysis cup (3). The constant temperature (2) of the water bath (4) was kept at $37^{\circ} \mathrm{C}$ by adjusting the thermostat magnetic stirrer (5). After $4 \mathrm{~h}, 1.0$ $\mathrm{ml}$ of the dialysis solution (3) was collected with the sampling tube $(6)$ and the PFOA concentration $\left(c_{\mathrm{L}}\right)$ was determined by spectrophotometry.

\section{ITC measurement}

By means of a ITC device, PFOA solution $(2.50 \mathrm{mM}$ in $\mathrm{pH}$ 7.40 BR buffer) was injected about 40 times in $6-\mu$ l increments at 3-min intervals into an isothermal cell containing HSA $(10.0 \mu \mathrm{M}$ in $\mathrm{pH} 7.40 \mathrm{BR}$ buffer). The cell temperature was maintained at $37^{\circ} \mathrm{C}$ and all the solutions contained $0.15 \mathrm{M} \mathrm{NaCl}$. Heats of dilution of PFOA, obtained separately by injecting into the buffer, were used to correct the data. The corrected heats were divided by the number of moles injected and analyzed using the Origin software (version 7.0).

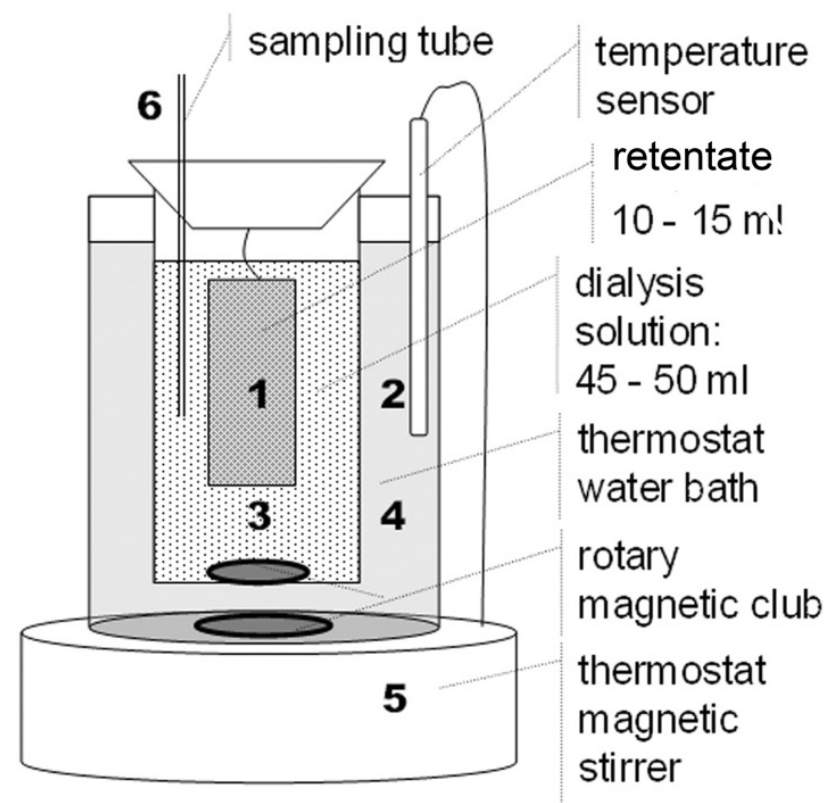

Figure 7

The new dialyzer was designed as illustrated: (I) semi-permeable membrane with $15.0 \mathrm{ml}$ of retentate; (2) - the temperature sensor for maintaining the reaction at constant $37^{\circ} \mathrm{C}(3)$ - Dialysis solution less than $50.0 \mathrm{ml}$; (4) - water bath at constant $37^{\circ} \mathrm{C}$. The apparatus was placed on a thermostated magnetic stirrer (5) and rotary magnets were used to mix solutions 3 and 4 thoroughly. The PFOA concentration in solution (3) was determined from the sampling tube (6).

\section{$C D$ measurement}

BR buffer (1.0 ml, pH 7.40) was mixed with $0.010 \mathrm{mM}$ HSA in three flasks; or $1.00 \mathrm{mM}$ PFOA was added and the solutions were diluted to $10.0 \mathrm{ml}$ with distilled water. Simultaneously, a reagent blank without PFOA was prepared. Before measurement, all the solutions were diluted from 0.1 to $10.0 \mathrm{ml}$ with $10 \%$ BR buffer. Each sample was allowed to equilibrate for $15 \mathrm{~min}$, then injected into a 0.1 $\mathrm{cm}$ light path cell, and the mean residue ellipticity (MRE) of HSA was measured between 195 and $250 \mathrm{~nm}$ by spectropolarimetry. 


\section{Authors' contributions}

LLW carried out all of the experimental operations except ITC measurement. HWG designed research and wrote the paper. NYG treated the data. FFC performed ITC measurement. LC provided the detection method. All authors read and approved the final manuscript.

\section{Acknowledgements}

This work was supported by the National Major Project of Science \& Technology Ministry of China (Grant No.2008ZX0742I-002) and the State Key Laboratory Foundation of Science and Technology Ministry of China (Grant No. PCRRK08003). We would like to thank Dr. Shao-Feng Luo of USTC for his help with ITC measurement and Dr. William Gelb and Dr. Xue-Ling Ao for their assistances in use of the computer programs and data analysis.

\section{References}

I. Stokstad E: Environmental research - DuPont settlement to fund test of potential toxics. Science 2006, 311:26-27.

2. Wania FA: Global mass balance analysis of the source of perfluorocarboxylic acids in the Arctic ocean. Environ Sci Technol 2007, 4I:4529-4535.

3. Lau C, Butenhoff JL, Rogers JM: The developmental toxicity of perfluoroalkyl acids and their derivatives. Toxicol Appl Pharmacol 2004, 198(2):23I-24I.

4. Maestri L, Negri S, Ferrari M, Ghittori S, Fabris F, Danesino P, Imbriani $M$ : Determination of perfluorooctanoic acid and perfluorooctanesulfonate in human tissues by liquid chromatography single quadrupole mass spectrometry. Rapid Commun Mass Spectrom 2006, 20:2728-2734.

5. Karrman A, Ericson I, van BB, Darnerud PO, Aune M, Glynn A, Lignell $S$, Lindstrom G: Exposure of perfluorinated chemicals through lactation, levels of matched human milk and serum and a temporal trend, 1996-2004, in Sweden. Environ Health Perspect 2007, I I 5(2):226-230.

6. Calafat AM, Kuklenyik Z, Reidy JA, Caudill SP, Tully J, S Needham LL Serum concentrations of II polyfluoroalkyl compounds in the US population, Data from the National Health and Nutrition Examination Survey NHANES. Environ Sci Technol 2007, 41:2237-2242.

7. Abbott BD, Wolf CJ, Schmid JE, Das KP, Zehr RD, Helfant L, Nakayama S, Lindstrom AB, Strynar MJ, Lau C: Perfluorooctanoic acid-induced developmental toxicity in the mouse is dependent on expression of peroxisome proliferator-activated receptor-alpha. Toxicol Sci 2007, 98:57I-58।.

8. Martin MT, Brennan RJ, Hu WY, Ayanoglu E, Lau C, Ren HZ, Wood CR, Corton JC, Kavlock RJ, Dix DJ: Toxicogenomic study of triazole fungicides and perfluoroalkyl acids in rat livers predicts toxicity and categorizes chemicals based on mechanisms of toxicity. Toxicol Sci 2007, 97:595-6/3.

9. Maras M, Vanparys C, Muylle F, Robbens J, Berger U, Barber JL, Blust $\mathrm{R}$, Coen DW: Estrogen-like properties of fluorotelomer alcohols as revealed by MCF-7 breast cancer cell proliferation. Environ Health Persp 2006, I I 4: 100-105

10. Yeung LWY, Guruge KS, Yamanaka N, Miyazaki S, Lam PKS: Differential expression of chicken hepatic genes responsive to PFOA and PFOS. Toxicology 2007, 237: I I|- 125.

II. Service RF: Meeting - American Chemical Society: Safer alternative could replace widespread contaminant. Science 2005, 309:1810

12. Washburn ST, Bingman TS, Braithwaite SK, Buck RC, Buxton LW, Clewell HJ, Haroun LA, Kester JE, Rickard RW, Shipp AM: Exposure assessment and risk characterization for perfluorooctanoate in selected consumer articles. Environ Sci Technol 2005 39:3904-3910.

13. He XM, Carter DC: Atomic structure and chemistry of human serum albumin. Nature 1992, 358:209-215.
14. Bhattacharya AA, Grune T, Curry S: Crystallographic analysis reveals common modes of binding of medium and long-chain fatty acids to human serum albumin. J Mol Biol 2000, 303:72I-732.

15. Kragh-Hansen U: Molecular aspects of ligand binding to serum albumin. Pharmacol Rev 198I, 33:17-53.

16. Purcell M, Neault JF, Malonga $\mathrm{H}$, Arakawa H, Carpentier R, TajmirRiahi HA: Interaction of atrazine and 2, 4-D with human serum albumin studied by gel and capillary electrophoresis FTIR spectroscopy. Biochim Biophys Acta 200I, I 548: I 29-I 38

17. Berger V, Gabriel AF, Sergent T, Trouet A, Larondelle Y, Schneider Y]: Interaction of ochratoxin A with human intestinal Caco-2 cells, possible implication of a multidrug resistance-associated protein MRP2. Toxicol Lett 2003, 140:465-476.

18. Silva D, Cortez CM, Cunhua-Bastos J, Louro SRW: Methyl parathion interaction with human and bovine serum albumin. Toxicol Lett 2004, 147:53-61.

19. Uddin SJ, Shilpi JA, Murshid GMM, Rahman AA, Sarder MM, Alam MA Determination of the binding sites of arsenic on bovine serum albumin using warfarin site-I specific probe and diazepam site-II specific probe. J Biol Sci 2004, 4:609-6I2.

20. Han X, Snow TA, Kemper RA, Jepson GW: Binding of Perfluorooctanoic Acid to Rat and Human Plasma Proteins. Chem Res Toxicol 2003, 16:775-78।.

21. Han X, Hinderliter PM, Snow TA, Jepson GW: Binding of Perfluorooctanoic Acid to Rat Liver - form and Kidney - form $\alpha 2 u$ - Globulins. Drug Chem Toxicol 2004, 27:34I-360.

22. Zhang X, Chen L, Fei XC, Ma YS, Gao HW: Binding of PFOS to serum albumin and DNA: insight into the molecular toxicity of perfluorochemicals. BMC Mol Biol 2009, 10:16.

23. Gao HW, Xu Q, Chen L, Wang SL, Wang Y, Wu LL, Yuan Y: Potential protein toxicity of synthetic pigments, binding of poncean S to human serum albumin. Biophys J 2008, 94:906-917.

24. Yang M: Molecular recognition of DNA targeting small molecule drugs. J Beijing Med Univ 1998, 30:97-99.

25. Cooper A, McAlpine A, Stockley PG: Calorimetric studies of the energetics of protein-DNA interactions in the $E$. coli methionine repressor MetJ system. FEBS Lett 1994, 348:4 I-45.

26. Kamiya M, Torigoe H, Shindo H, Sarai A: Temperature dependence and sequence specificity of DNA triplex formation, an analysis using isothermal titration calorimetry. J Am Chem Soc 1996, I I 8:4532-4538.

27. Luque I, Todd MJ, Gomez J, Semo N, Freire E: Molecular basis of resistance to HIV-I protease inhibition, a plausible hypothesis. Biochemistry 1998, 37:579|-5797.

28. Cabot R, Hunter CA: Non-covalent interactions between iodoperfluorocarbons and hydrogen bond acceptors. Chem Comm 2009

29. Xu Z, Liu XW, Ma YS, Gao HW: Interactions of nano-TiO2 with lysozyme: insights into the enzyme toxicity of nanosized particles. Environ Sci Pollut Res Int 2009.

30. Li L, Gao HW, Ren JR, Chen L, Li YC, Zhao JF, Zhao HP, Yuan Y: Binding of Sudan II and IV to lecithin liposomes and E. coli membranes: insights into the toxicity of hydrophobic azo dyes. BMC Struct Biol 2007, 7:16.

31. Incardona JP, Collier TK, Scholz NL: Defects in cardiac function precede morphological abnormalities in fish embyos exposed to polycyclic aromatic hydrocarbon. Toxicol Appl Pharmacol 2004, 196:19|-205.

32. Wu LL, Chen L, Song C, Liu XW, Deng HP, Gao NY, Gao HW: Potential enzyme toxicity of perfluorooctanoic acid. Amino Acids 2009. 